\title{
Tyre Volume and Pressure Effects on Impact Attenuation during Mountain Bike Riding
}

\author{
Paul W. Macdermid, Matthew C. Miller, Fiona M. Macdermid, and Philip W. Fink
}

Massey University, College of Health, School of Sport \& Exercise, Palmerston North 4474, New Zealand

Correspondence should be addressed to Paul W. Macdermid; p.w.macdermid@massey.ac.nz

Received 19 April 2015; Accepted 22 July 2015

Academic Editor: Chao Tao

Copyright (C) 2015 Paul W. Macdermid et al. This is an open access article distributed under the Creative Commons Attribution License, which permits unrestricted use, distribution, and reproduction in any medium, provided the original work is properly cited.

Exposure to impacts and vibrations has been shown to be detrimental to cross country mountain bike performance and health. Therefore, any strategy aimed at attenuating such exposure is useful to participants and/or industry. The purpose of this study was to assess the influence of tyre size and tyre inflation pressure on exposure to impacts. Participants completed nine trials of a technical section (controlled for initial speed and route taken) including nine separate conditions involving three tyre sizes and three tyre inflation pressures normalised per tyre. Performance was determined by time to negotiate the technical section while triaxial accelerometers recorded accelerations $(128 \mathrm{~Hz})$ to quantify impact exposure and the subsequent effects on soft tissue response. Increases in tyre size within the range used improved performance $(P<0.0001)$ while changes to tyre inflation pressure had no effect $(P=0.6870)$ on performance. Larger tyre sizes and lower tyre inflation pressures significantly $(P<0.0001)$ reduced exposure to impacts which could be augmented or negated due to an interaction between tyre size and inflation pressure $(P<0.0001)$. It is recommended that mountain bikers use larger tyres, inflated to the moderate pressures used within this study, in order to increase performance and reduce the risk of overuse injuries.

\section{Introduction}

Initial studies into the work demand of Olympic format cross country mountain biking (XCO-MTB) identified disassociation of physiological variables (heart rate (HR) and oxygen consumption $\left.\left(\mathrm{V}_{2}\right)\right)$ with power output [1-4]. This disassociation was established through analysis of terrain data, showing that throughout periods of zero propulsive work XCO-MTB athletes are not afforded the same recovery as per riding over smooth surface terrain [5]. Laboratory studies [6, 7] showed that exposure to vibrations increased physiological strain [7] which was associated with a decreased time to exhaustion [6]. Subsequent field based research [8] drew attention to the increased nonpropulsive work component of downhill mountain biking through an increase in muscular contraction of the upper body. This has since been linked to vibration damping plus shock attenuation and is reflected by significant reductions at the lower back and head [9] compared to points of contact with the bicycle. The purpose of this is to protect the central nervous system from injury to the spine, spinal cord, or brain [6]. Ultimately, such damping increases motor unit involvement for a given force production, resulting in a decreased rider economy $[10,11]$. Understanding the interaction between surface terrain and rider economy is important in order to not only increase overall performance but also reduce the risk of overuse injuries. Therefore, any strategy with the potential to lessen vibration exposure warrants investigation in order to determine authenticity.

Initial work in this area has identified the value of the full suspension bicycle in reducing vibration exposure [12] albeit with negative consequences on performance explained via the increased weight component. However, the international governing organisation of XCO-MTB (UCI) has no rules regarding the wheel size competitors use which could possibly affect vibrations experienced and overall performance [9]. Only one such study has been published at present, discovering that increased wheel diameter instigated greater vibration exposure and thus the level of damping required [9]. While the result was unexpected, it could be explained via 
TABLE 1: Characteristics of the tyres used during the study.

\begin{tabular}{lcccccc}
\hline Tyre model & $\Sigma T_{\mathrm{wt}}(\mathrm{g})$ & ISO/ETRTO $(\mathrm{mm})$ & Est. $T_{\mathrm{vol}}\left(\mathrm{cm}^{3}\right)$ & Manufacturer technology & TPI & Recommended tyre pressure $(\mathrm{psi})$ \\
\hline CycloXKing & 760 & $35-622$ & 1980 & Performance & $3 / 180$ & $56-85$ \\
XKing & 1380 & $55-622$ & 5050 & Performance & $3 / 180$ & $50-65$ \\
XKing & 1470 & $60-622$ & 6060 & Performance & $3 / 180$ & $50-65$ \\
\hline
\end{tabular}

an increase in the speed travelled per work done leading to the positive outcome of improved performance over a XCO-MTB lap inclusive of additional rotational weight [9]. Despite the fact that performance improved, the increased vibration exposure is still an issue with respect to potential overuse injuries and further performance enhancement. Supplementary to the wheel size increase, the tyre size combined with its inflated air pressure (psi) could assist recreational and competitive off-road cyclists to achieve a more comfortable experience. Work investigating related issues in farm machinery operation have shown that increasing tyre inflation pressures were capable of considerable changes (up to $75 \%$ ) in estimated vibration exposure [13]. This is further supported in wheelchair users [14]. Yet paradoxically, reduced tyre inflation pressures increased rolling resistance by $35 \%$ amongst wheelchair users $[14,15]$. Quantifying such relationships in terms of comfort and performance during mountain biking is important to understand.

The objective of this study was, therefore, to quantify the influence of tyre size and inflation pressure on impact attenuation transmitted from surface terrain to bicycle and the cyclist during the negotiation of a technical component similar to that experienced during XCO-MTB racing. It was hypothesised that larger tyre sizes would lower the level of impact exposure experienced at the point of contact between bicycle and body, while higher tyre inflation pressures within tyre sizes would increase the level of impact exposure. Additionally, the benefit of tyre size could be negated through high tyre pressures.

\section{Method}

Twelve experienced mountain bikers (National (NZ) level cross-country athletes) consented in accordance with the University Human Ethics Committee to take part in this study. All participants used the same bicycle (GT Zaskar elite $29^{\prime \prime}$ Full Suspension, Optimized Force Constructed Carbon, USA), adjusted to personal requirements prior to the trial, and thus controlling posture. The bicycle was fitted with a front (Rockshox Recon $100 \mathrm{~mm}$, Solo Air, USA) and rear suspension (Fox Float CTD, USA) system, set as per the manufacturers recommendations for specific body weights. However, both front suspension and rear suspension were then switched to lock-out mode in order to allow no mechanical damping as a result of suspension. Therefore, any effect on acceleration measured would be as a result of the intervention(s).

2.1. Field Test Trial. The experimental protocol involved the negotiation of two flights of eight steps (dimension, $26 \times$ $13 \mathrm{~cm}$ ), equal throughout, with the two flights separated by

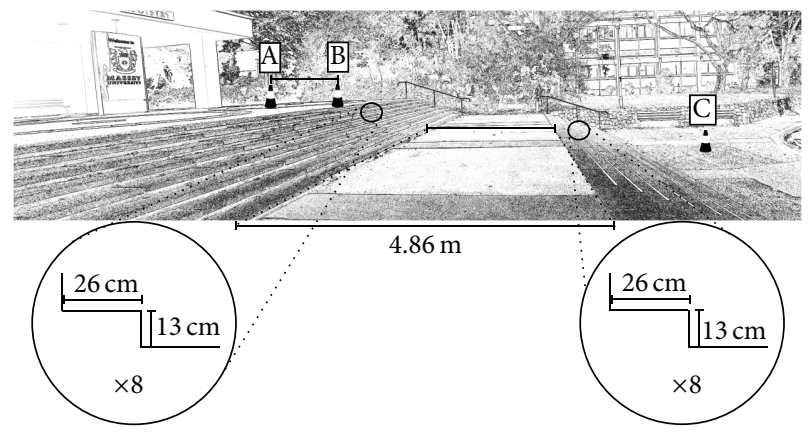

FIGURE 1: Pictorial representation of the experimental protocol, where A signifies the start point with the front wheel, $\mathrm{B}$ indicates the point at which timing commenced, and $\mathrm{C}$ is where timing ceased. The distance from A-B was dependent on the specific tyre rollout (see Table 1).

a distance of $4.86 \mathrm{~m}$ (Figure 1). This obstacle was chosen in order to simulate a moderate/typical technical downhill section on a cross country mountain bike course, while being able to control participant run up and the route taken. It was felt that this aspect would be uncontrollable whilst riding a cross country mountain bike trail.

Determination of the start position distance from the first step was equal to wheel roll-out distance for specific tyre sizes (Table 1). This permitted participants one complete pedal stroke, which started with the preferred lead foot at $45^{\circ}$ enabling them to hit point B (Figure 1) in the ready position (preferred foot and pedal at $\sim 90^{\circ}$ angle) just prior to negotiation of the steps. The distance (A-B, Figure 1 ) was equalled at the bottom of the second flight of stairs to mark the finish (C, Figure 1) and allow the whole bicycle to have negotiated the second flight of steps. Front chainring (36 tooth) and rear cassette $\operatorname{cog}$ (14 tooth) were standardised for all participants throughout the study.

Participants completed six conditions, including three different tyres of the same tread pattern and construction, but differing in size and weight (Table 1). For each tyre, three tyre inflation pressures were selected based on the standard (2.2 Xking) XCO-MTB tyre and the typical inflation pressure values used by expert XCO-MTB cyclists and cited elsewhere [16]. The standardised tyre inflation pressure value (tyre inflation pressure (moderate) for Xking 2.2) was 0.3 psi per total weight (Bike + fully clothed and helmeted cyclist).

In order to calculate a proportional value for the other conditions (nontypical XCO-MTB tyres including cycloXKing and Xking 2.4, Table 1) a ratio of estimated tyre volume between conditions was used. This involved factorising the standardised value for the 2.2 Xking tyre by 1.629 and 0.868 


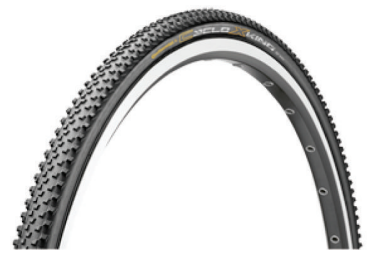

(a)
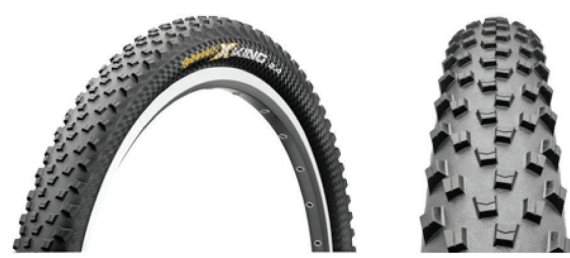

(b)

FIGURE 2: Pictorial image of the two main tyres ((a) cyclocross and (b) mountain bike).

for the cycloXKing and Xking 2.4 tyres, respectively. Estimated tyre volume (Est. $T_{\text {vol }}$ ) was based on ISO/ETRTO measurements [17] and Pappus's centroid theorem for calculating volume of a torus $\left(\mathrm{cm}^{3}\right)$ [16]. From these values further factorising took place to establish a normalised and proportional low $\left(0.666^{*}\right)$ and high $\left(1.333^{*}\right)$ tyre inflation pressure for all tyres. Comparison of the three tyres and the inflation pressures can be seen in Figures 2 and 3.

2.2. Outcome Measures. Wireless, triaxial accelerometers, magnetometers, and gyroscopes with a reported accuracy $0.0012 \mathrm{~m} \cdot \mathrm{s}^{2} \cdot \sqrt{ } \mathrm{Hz}^{-1}$ (Emerald, APDM, OR, USA) were used in a synchronised data-logging mode to measure accelerations as previously reported during XCO-MTB [9]. Through use of a trigger to switch on the accelerometers, performance time (s) was also recorded from point B-C, Figure 1. The accelerometers were placed on the lower left arm (frontal distal position); left lower leg (frontal, distal position); seat post (within $10 \mathrm{~cm}$ of the saddle-rider contact area); lumbar region of the lower back; and medial forehead [9]. All data was sampled at $128 \mathrm{~Hz}$, logged to a standard personal computer, converted to a hierarchal data format file (.h5), and processed using MATLAB R2014a. All data were analysed for total $\left(x-, y_{-}\right.$, and $z$-axis), vertical ( $z$-axis), and horizontal ( $x$ - and $y$-axis) accelerations. Root mean squares (RMS) of the accelerations were calculated to quantify overall effect of conditions, while spectral analysis was performed (Fast Fourier Transform) to determine maximum magnitude $\left(\mathrm{m}^{2} \cdot \mathrm{s}^{-4}\right)$, maximum frequency $(\mathrm{Hz})$, and quantification of movements as low $(<5 \mathrm{~Hz})$ and high $(>5 \mathrm{~Hz})$ power.

2.3. Statistical Analyses. Descriptive (mean $\pm \mathrm{SD}$ ) were calculated for all variables measured during each condition.

Two-way repeated analysis of variance (ANOVA), with two within-subject variables (tyre size $*$ tyre inflation pressure), was used to test differences in time to complete the protocol with a Tukey's post hoc comparison within tyre inflation pressure for each tyre.

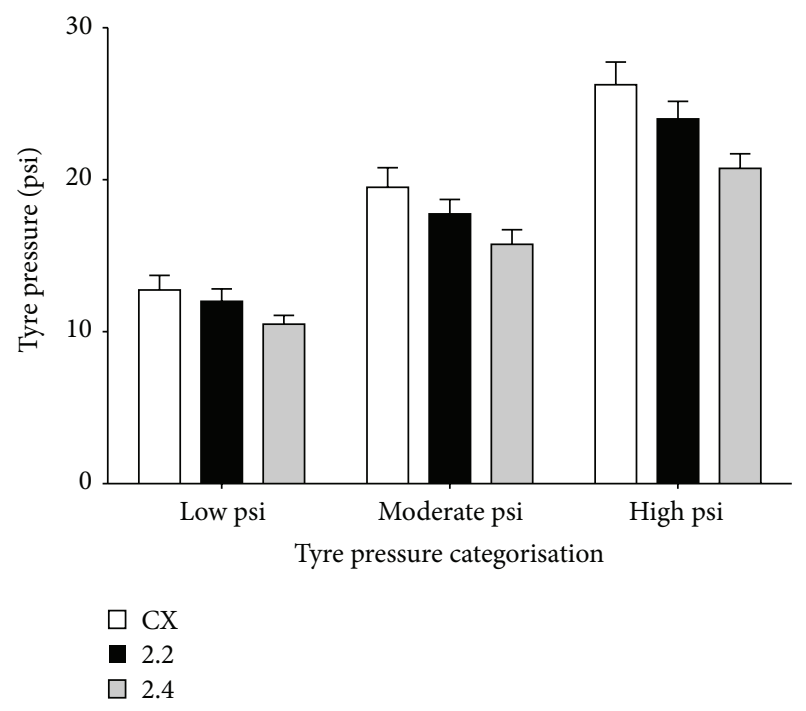

FIGURE 3: Comparison of the three tyres and the respective inflation pressures used.

Acceleration data comparisons were made via univariate analysis of variance (three-way ANOVA), including withinsubject variables, tyre size, tyre inflation pressure, and accelerometer location, tested for main effects and interactions (tyre size $*$ tyre inflation pressure $*$ accelerometer location; tyre size $*$ tyre inflation pressure; tyre size $*$ acceleration location; and tyre inflation pressure $*$ accelerometer location). Where significant difference was found, the main effect was analysed using Bonferroni post hoc testing pairwise comparison.

All statistical analyses were performed using IBM SPSS statistics 20, significance set at $P<0.05$.

\section{Results}

3.1. Performance Analysis. Participants completed a simulated technical component typical of the impacts associated with a XCO-MTB course [9].

Two-way ANOVA identified significant main effects for tyre size $\left(F_{(2,33)}=44.46, P<0.0001\right)$ but not tyre inflation pressures within tyres $\left(F_{(2,33)}=1.407, P=0.2591\right)$, for time to complete the trial (Figure 4$)$. There was no interaction $\left(F_{(4,66)}=0.5676, P=0.6870\right)$ between tyre size and tyre inflation pressure.

3.2. Acceleration Data Analysis. Three-way ANOVA of total acceleration amplitude (RMS) showed that there was a significant main effect for tyre size $\left(F_{(2,33)}=72.847, P<0.0001\right)$, tyre inflation pressure $\left(F_{(2,33)}=38.230, P<0.0001\right)$, and accelerometer locations $\left(F_{(5,66)}=72.847, P<0.0001\right)$, plus an interaction $\left(F_{(9,132)}=6.114, P=0.0001\right)$ between tyre size and tyre inflation pressures (Figures 5(a)-5(c)). Key findings from post hoc analysis showed differences for tyre size $(P<$ $0.0001)$, between the cycloXKing (cx) and 2.2 XKing (95\% CI, 0.907-2.102), cycloXKing and 2.4 XKing (95\% CI, 2.4063.601), and, 2.2 and 2.4 XKing (95\% CI, 0.901-2.096); tyre 


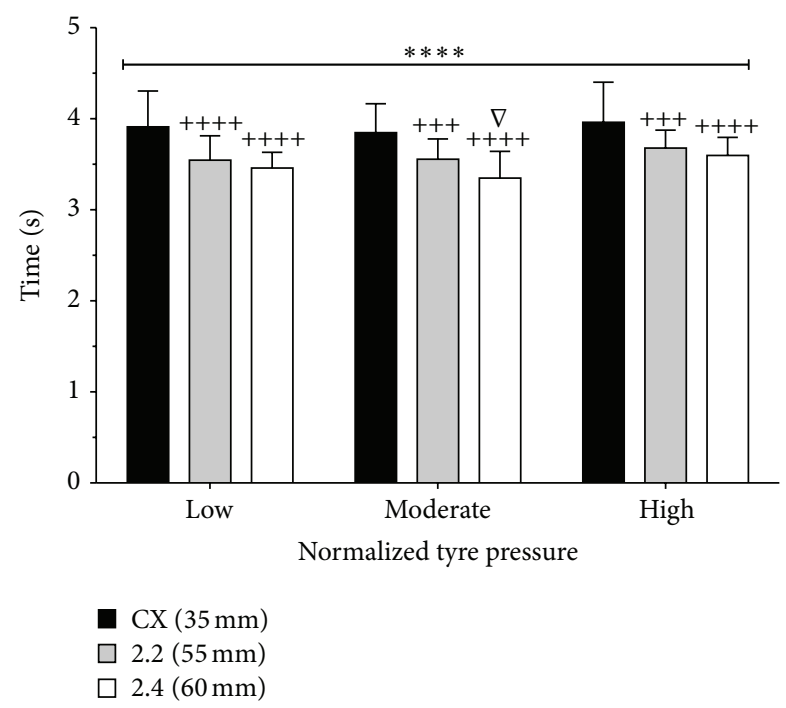

FIgURE 4: Mean \pm SD for performance time (s) over the trial protocol (Figure 1$).{ }^{* * * *}(P<0.0001)$ main effect of tyre; post hoc differences when comparing tyres for within-tyre inflation pressures when compared to CX: ${ }^{+++}(P<0.0001),{ }^{+++}(P<0.001)$, and 2.2; ${ }^{\nabla}(P<0.05)$.

inflation pressure $(P<0.05)$, between pressure low and moderate (95\% CI, -1.261--0.066), low and high (95\% CI, -2.724--1.529), and, moderate and high (95\% CI, $-2.060-$ -0.866). Multiple comparisons between the accelerometer locations were significantly different $(P<0.0001)$ except in the case of the handlebar and seat post $(P=0.824,95 \% \mathrm{CI}$ $-0.360-1.714)$ and the lower back and forehead $(P=0.092$, 95\% CI -0.069-2.005).

Significant main effects for vertical acceleration amplitude (RMS) for tyre size $\left(F_{(2,33)}=16.010, P<0.0001\right)$, tyre inflation pressure $\left(F_{(2,33)}=17.319, P<0.0001\right)$, and accelerometer location $\left(F_{(5,66)}=2654.3, P<0.0001\right)$ were found (Figures 5(d)-5(f)). There were significant interactions between tyre size and accelerometer location $\left(F_{(7,99)}=4.657\right.$, $P<0.0001)$ and, tyre inflation pressure and accelerometer location $\left(F_{(7,99)}=4.253, P<0.0001\right)$. Post hoc analysis showed significant differences $(P<0.0001)$ for tyre size between cycloXKing and 2.2 XKing (95\% CI, 0.360-1.163), and, cycloXKing and 2.4 XKing (95\% CI, 0.466-1.270); normalised tyre inflation pressure between low and high (95\% CI, -1.347--0.5440), and, moderate and high (95\% CI, -0.1666-0.637). Multiple comparisons between accelerometer locations were significantly different $(P<0.01)$ except in the case of the handlebar and wrist $(P=1.000)$ and lower back and forehead $(P=1.000)$.

Horizontal accelerations (Figures $5(\mathrm{~g})-5(\mathrm{i}))$ showed main effects for tyre size $\left(F_{(2,33)}=35.895, P<0.0001\right)$, tyre inflation pressure $\left(F_{(2,33)}=10.460, P<0.0001\right)$, and accelerometer location $\left(F_{(5,66)}=1548.645, P<0.0001\right)$, with interactions between tyre size $*$ tyre inflation pressure $\left(F_{(4,66)}=\right.$ $3.111, P=0.0150)$, tyre size $*$ accelerometer location $\left(F_{(7,99)}=10.116, P<0.0001\right)$, and tyre inflation pressure $*$ accelerometer location $\left(F_{(7,99)}=1.866, P=0.0470\right)$. Post hoc analysis identified differences between all tyre sizes $(P<$ $0.01)$, between tyre inflation pressures low and high $(P<$ $0.0001)$ and moderate and high $(P=0.0109)$, and between all accelerometer locations $(P<0.05)$.

Three-way ANOVA of spectral analysis, maximum frequency (Table 2) data provided a significant interaction between tyre size and accelerometer location $\left(F_{(7,99)}=6.700\right.$, $P<0.0001)$ with a main effect of tyre size $\left(F_{(2,33)}=12.553\right.$, $P<0.0001)$ and accelerometer location $\left(F_{(5,66)}=51.011, P<\right.$ $0.0001)$. Post hoc analysis identified differences between tyre sizes cycloXKing and 2.2 XKing (95\% CI, -0.2865--0.7662) and cycloXKing and 2.4 XKing (95\% CI, -0.3017--0.0919). Data for maximum magnitude (Table 3) identified significant main effects for tyre size $\left(F_{(2,33)}=34.420, P<0.0001\right)$, tyre inflation pressure $\left(F_{(2,33)}=22.864, P<0.0001\right)$, and acceleration position $\left(F_{(5,66)}=3336.605, P<0.0001\right)$ with interactions between tyre size * accelerometer position $\left(F_{(7,99)}=10.852, P<0.0001\right)$ and tyre inflation pressure $*$ accelerometer location $\left(F_{(7,99)}=4.271, P<0.0001\right)$. Post hoc analysis showed differences between tyre sizes occurred for cycloXKing and 2.2" Xking $(P=0.0050)$, cycloXKing and $2.4^{\prime \prime}$ XKing $(P<0.0001)$, and, $2.2^{\prime \prime}$ XKing and $2.4^{\prime \prime}$ XKing $(P<0.0001)$; tyre inflation pressure differences occurred between low and moderate $(P=0.026)$, low and high $(P<0.0001)$, and moderate and high $(P=0.0002)$; while differences between all accelerometer positions $(P<0.0500)$ except lower back and forehead $(P>0.0500)$ occurred.

Power data separated for low $(<5 \mathrm{~Hz})$ frequency (Table 4$)$ identified significant main effects for tyre size $\left(F_{(2,33)}=5.157\right.$, $P=0.0060)$ and accelerometer position $\left(F_{(5,66)}=1855.902\right.$, $P<0.0001)$, interactions between tyre size and accelerometer position $\left(F_{(7,99)}=1.990, P=0.0320\right)$, and tyre inflation pressure and accelerometer position $\left(F_{(7,99)}=1.998, P=0.0310\right)$. Post hoc differences for tyre size between cycloXKing and $2.2^{\prime \prime}$ XKing (95\% CI, $-0.4853-0.0693, P=0.0040$ ) were present and all accelerometer positions except the handlebar and seat post $(P=0.6330)$. High $(>5 \mathrm{~Hz})$ frequency (Table 4$)$ showed significant main effects for tyre inflation pressure $\left(F_{(2,33)}=17.516, P<0.0001\right)$ and accelerometer position $\left(F_{(5,66)}=5190.764, P<0.0001\right)$, with interactions for tyre size $*$ tyre inflation pressure $\left(F_{(4,66)}=4.210, P=0.0020\right)$, tyre size $*$ accelerometer position $\left(F_{(7,99)}=9.575, P=0.0070\right)$, and tyre inflation pressure $*$ accelerometer position $\left(F_{(7,99)}=\right.$ 2.091, $P=0.0230)$. Post hoc analysis identified differences within the tyre inflation factor, between low and high pressure (95\% CI, $-1.5404-0.6302, P<0.0001)$ and moderate and high pressure (95\% CI, $-1.2441--0.3339, P<0.0001)$. All accelerometer positions were different $(P<0.0001)$ except in the case of the handlebar and wrist $(P=0.7560)$ and the lower back and head $(P=1.0000)$.

\section{Discussion}

The aim of this study was to quantify the influence of tyre size and the normalised tyre inflation pressure on exposure to impacts and their interactions typical of that experienced whilst riding on a cross country mountain bike trail. The main findings were as follows: (a) increases in tyre size led to 


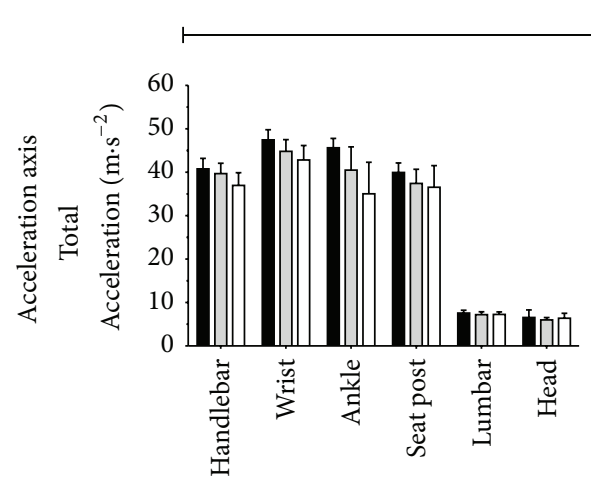

(a)

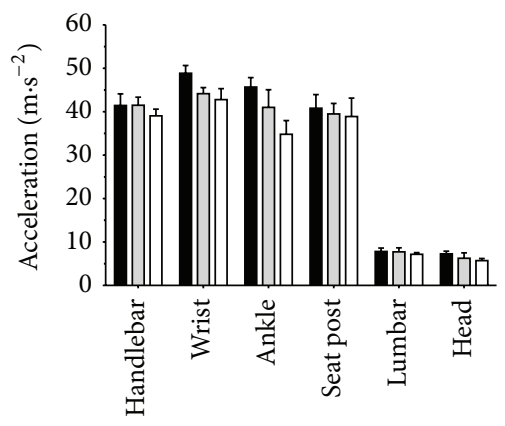

(b)

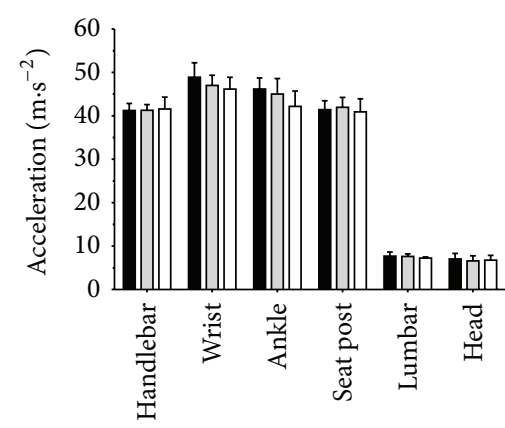

(c)

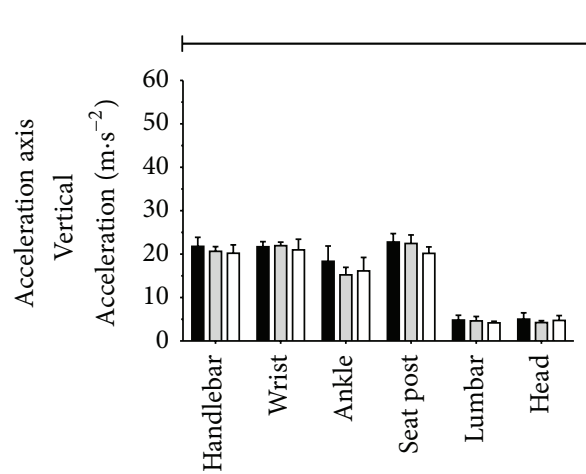

(d)

EfEE; $\$ \$ \$ \$ ; \otimes \otimes \otimes \otimes ; \varnothing \varnothing \varnothing \varnothing ; \nabla \nabla \nabla \nabla$

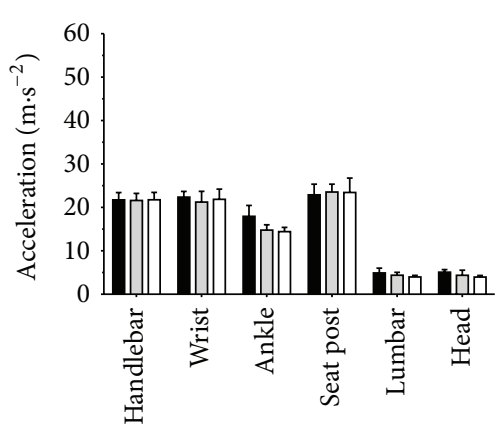

(e)

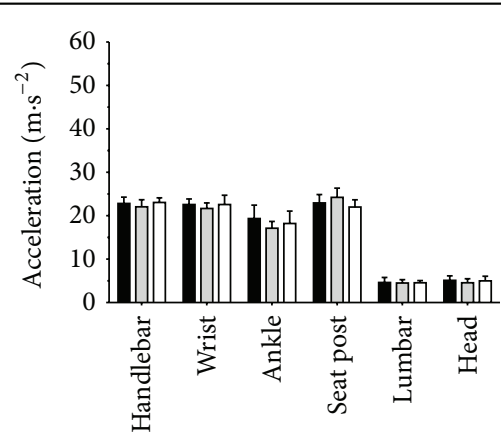

(f)

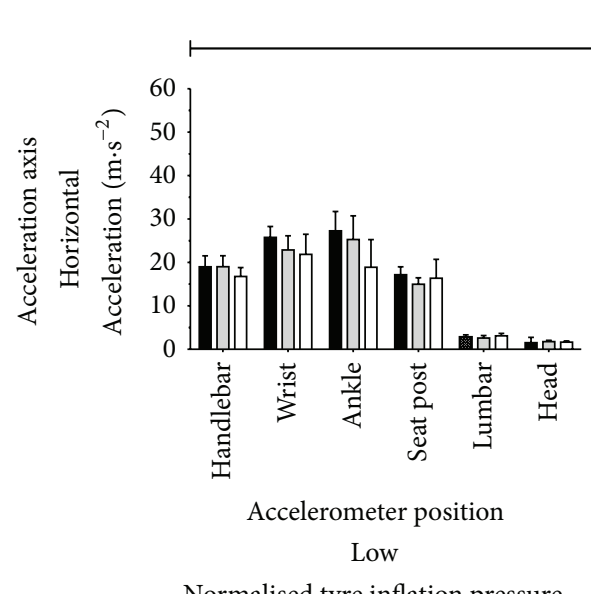

Normalised tyre inflation pressure

(g)

$* * ; \mathcal{E E E} ; \$ \$ \$ \$ ; \otimes \otimes \otimes \otimes ; \varnothing \varnothing \varnothing \varnothing ; \nabla \nabla \nabla \nabla$

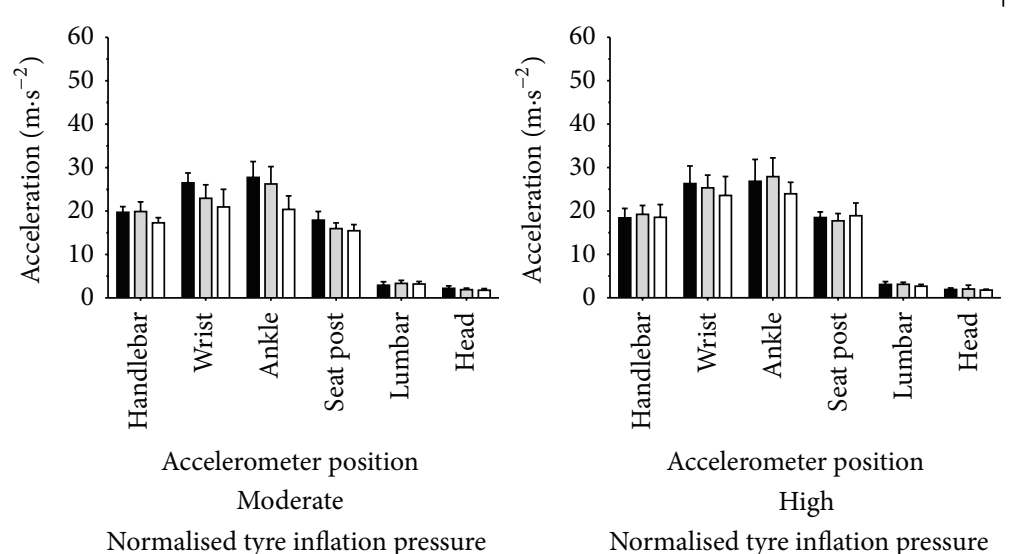

(h)

(i)

Figure 5: Comparison between tyres (CycloXKing (black bar), 2.2 XKing (gray bar), and 2.4 XKing (white bar)) and three normalised tyre inflation pressures characterised as low (1), normal (2), and high (3) for (a)-(c). Total accelerations: (d)-(f). Vertical accelerations; (g)(i). Horizontal accelerations, where $*$ refers to the interaction for tyre size $*$ tyre pressure $\left({ }^{* * * *} P<0.0001\right.$; $\left.{ }^{* *} P<0.01\right)$, $\$$ refers to the interaction for tyre size $*$ accelerometer location $\left({ }^{\$ \$ \$} P<0.0001\right)$, refers to the interaction for tyre pressure $*$ accelerometer location $\left({ }^{\mathfrak{E f E E}} P<\right.$ $0.0001) ;{ }^{\otimes \otimes \otimes}(P<0.0001)$ main effect of tyre size; ${ }^{\varnothing \varnothing \varnothing \emptyset}(P<0.0001)$ main effect of tyre pressure; ${ }^{\nabla \nabla \nabla}(P<0.0001)$ main effect of accelerometer location.

positive effects on performance compared to tyre inflation pressure when riding down rough terrain; (b) increases in tyre size decrease the level of impact exposure experienced at point of contact(s) with the bicycle and thus reduce nonpropulsive work load; (c) increased tyre inflation pressure intensifies exposure to acceleration exposure.
Increased exposure to impacts and vibrations associated with forwards momentum of an off-road cyclist are linked to increased nonpropulsive work [8], decreased efficiency [11], and performance $[6,7]$. The reduction of this nonpropulsive work is thus potentially important, with regard to competitive performance and the minimisation of overuse injury risk [18]. 


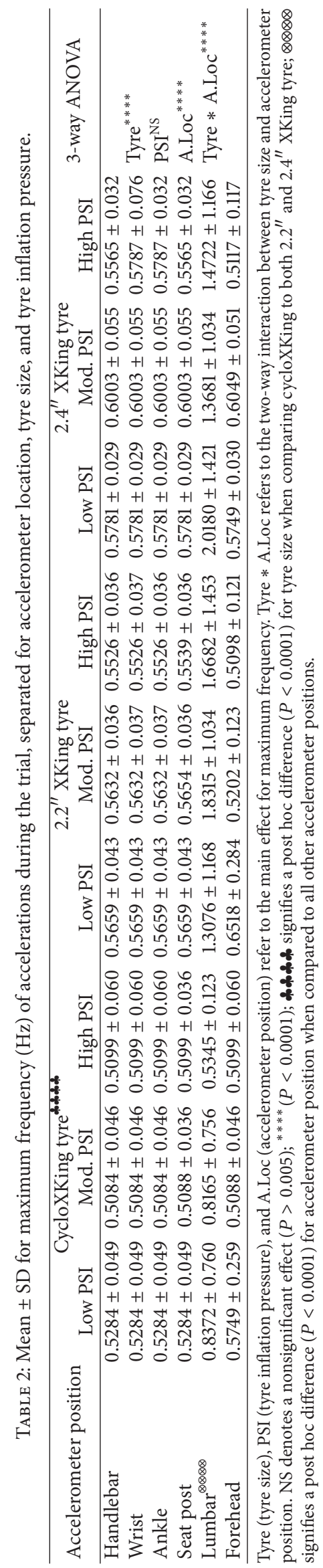




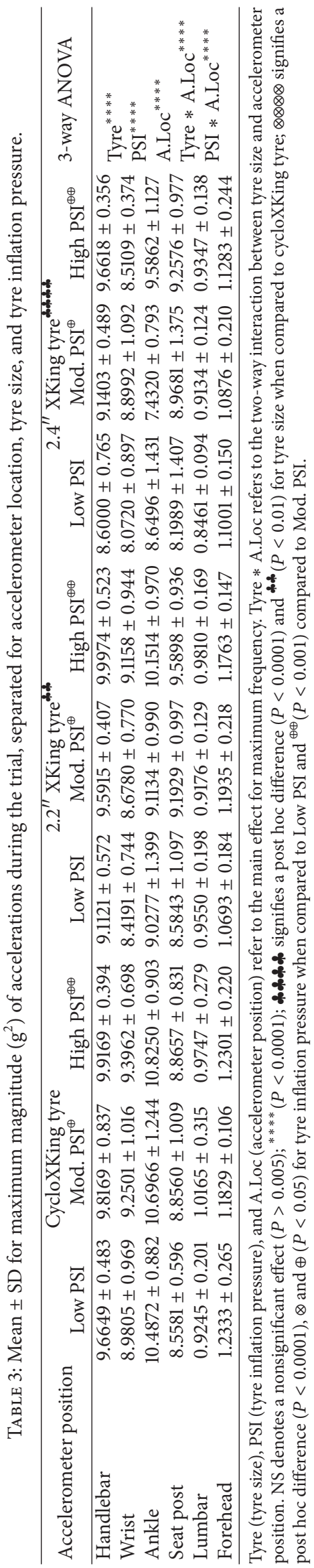




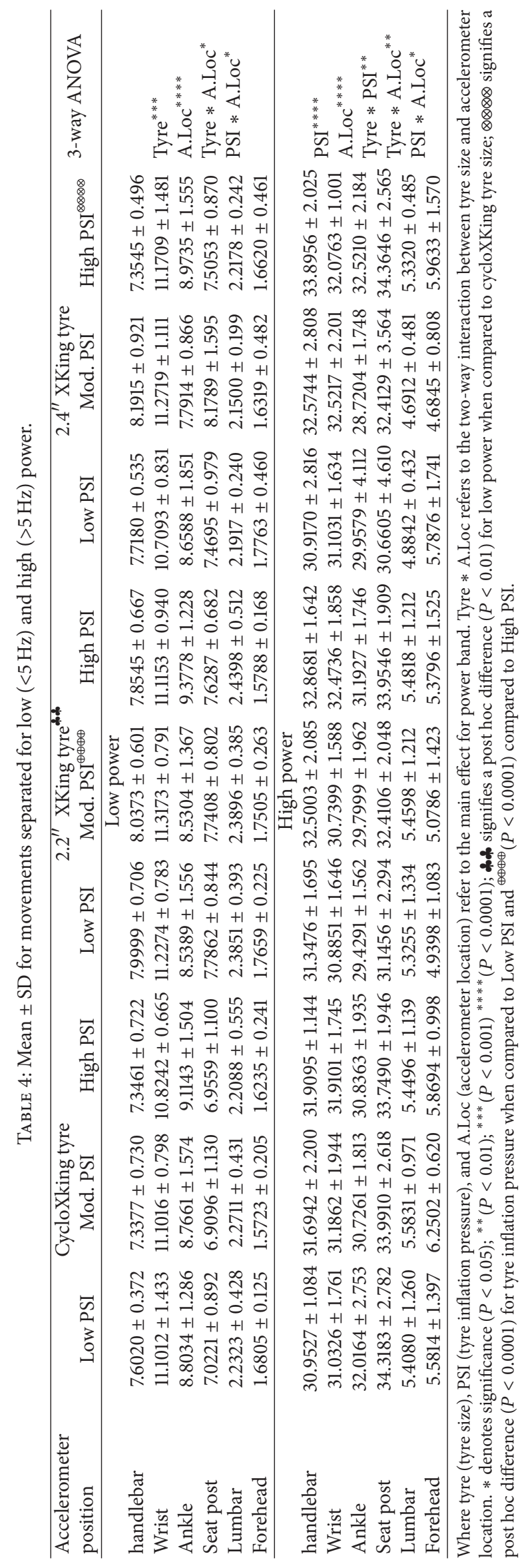


In the first instance Figure 4 identifies the highly significant $(P<0.0001)$ effect of tyre size on performance time with regard to normalised tyre inflation pressures. This is further exacerbated considering the typical tyre inflation pressure (moderate, Figure 3 ) used by competitive XCO-MTB athletes [16]. At this pressure, post hoc analysis identified differences between $2.2^{\prime \prime}$ and $2.4^{\prime \prime}$ XKing tyres, suggesting that tyre size could have considerable effect on performance.

While difficult to glean conclusive data regarding overall XCO-MTB performance from such a small downhill component of performance as collected in this study, it is worth noting that previous research has linked decreased vibration exposure to increased efficiency $[10,11]$. As such, the attenuation of accelerations experienced (Figure 5 and Tables 3 and 4) at the point of contact between human and bicycle (handlebar and seat post) as a result of increased tyre size could theoretically be connected to overall performance during complete race distance. This obviously assumes that the decrease in nonpropulsive work would reduce muscular and cognitive fatigue and consequentially increase performance. However, it is acknowledged that a complete XCO-MTB race entails a variety of surfaces and terrains, where the majority of time is spent cycling uphill on smoother surfaces that might actually suit a smaller, higher pressure tyre. As such, future research is needed to explore this aspect.

On the other hand, tyre inflation pressure does not seem to influence performance in this experiment (Figure 4), even though an increase in accelerations in all axes (Figure 5) related to an increase in magnitude (Table 3 ) rather than frequency (Table 2) was apparent. While interesting, the transient nature of the protocol used cannot corroborate the long term effects that racing for $\geq 90$ mins, with the observed increases in magnitude, would have on accumulated muscular fatigue. Based on previous laboratory work $[6,19]$ it is believed that XCO-MTB performance would be compromised over a complete race distance but requires confirmation.

Similar to previous work on the transference of accelerations during XCO-MTB [9], the data presented here shows that both the bicycle and the soft tissue are dissipating energy $[20,21]$ from the interaction of bicycle with surface terrain, implying a reduced nonpropulsive work component of XCOMTB as a result of increased tyre size. This is supported through two-way interactions between both tyre size $*$ accelerometer position and tyre inflation pressure $*$ accelerometer location for total, vertical, and horizontal accelerations (Figure 5); magnitude (Table 3); and low-high power distribution (Table 4). As such, the reduction in measures associated with acceleration exposure reported previously decreased at the point of interaction with the bicycle with an increase in tyre size. Importantly, this was accompanied by reductions at the soft tissue sites implying a reduced nonpropulsive work component of XCO-MTB as a result of increased tyre size. Alternatively, increases in tyre inflation pressure have the opposite and negative effect by increasing rider exposure to accelerations at the point of interface with bicycle and thus increase the non-propulsive component. Additionally, the controlled nature of this protocol may enable participants to alter body position or riding style dependent on tyre chracteristics not afforded during a racing situation.

\section{Conclusion}

This study set out to quantify the influence of tyre size and normalised tyre inflation pressure on exposure to impacts typical to cross country mountain bike riding. It was found that the larger the tyre size, within the range tested, the lower the level of impact exposure experienced at the point of contact between bicycle and body. This reduction meant participants performed less non-propulsive muscular work and performed better when compared to a smaller tyre of the same construction and tread pattern. Contrariwise, higher tyre inflation pressures were associated with an increase in the level of impact exposure and thus greater soft tissue work in order to attenuate the larger impacts. In addition, it was shown that increased tyre inflation pressure could interact negatively with tyre size, while increased tyre size could interact positively with tyre inflation pressure. As such, the effects of reduced exposure need to be assessed with regards to longer periods of time such as experienced in a mountain bike race or recreational ride.

\section{Practical Application}

It is recommended that participants (recreational and competitive) use a higher volume tyre over any smaller alternative within the range tested here. In doing so it is suggested that participants could improve performance, and likely reduce the risk of overuse injuries or increase the time spent riding for the same risk(s).

It is important to note that two-way interactions between tyre size and tyre inflation pressures suggest that the benefits of riding with a bigger tyre could be negated through the use of high tyre inflation pressure. Conversely, the use of lower tyre inflation pressures in smaller tyres could reduce exposure but must come with a warning of increased unreliability in terms of punctures and de-beading from the wheel rim.

\section{Future Research}

The findings of this study must now be verified over a complete XCO-MTB race lap, consisting of a variety of terrains to enable whole performance analysis and terrain specific section performance analysis.

\section{Conflict of Interests}

The authors declare that there is no conflict of interests regarding the publication of this paper.

\section{References}

[1] H. T. Hurst and S. Atkins, "Power output of field-based downhill mountain biking," Journal of Sports Sciences, vol. 24, no. 10, pp. 1047-1053, 2006.

[2] F. M. Impellizzeri and S. M. Marcora, "The physiology of mountain biking," Sports Medicine, vol. 37, no. 1, pp. 59-71, 2007. 
[3] P. W. Macdermid and S. Stannard, "Mechanical work and physiological responses to simulated cross country mountain bike racing," Journal of Sports Sciences, vol. 30, no. 14, pp. 14911501, 2012.

[4] B. Stapelfeldt, A. Schwirtz, Y. O. Schumacher, and M. Hillebrecht, "Workload demands in mountain bike racing," International Journal of Sports Medicine, vol. 25, no. 4, pp. 294-300, 2004.

[5] P. Macdermid, P. Fink, and S. Stannard, "The effects of vibrations experienced during road vs. off-road cycling," International Journal of Sports Medicine, 2015.

[6] B. Samuelson, L. Jorfeldt, and B. Ahlborg, "Influence of vibration on endurance of maximal isometric contraction," Clinical Physiology, vol. 9, no. 1, pp. 21-25, 1989.

[7] J. Titlestad, A. Fairlie-Clarke, M. Davie, A. Whittaker, and S. Grant, "Experimental evaluation of mountain bike suspension systems," Acta Polytechnica, vol. 43, no. 5, 2003.

[8] H. T. Hurst, M. Swarén, K. Hébert-Losier et al., "Influence of course type on upper body muscle activity in elite CrossCountry and Downhill mountain bikers during off Road Downhill Cycling," Journal of Science and Cycling, vol. 1, no. 2, pp. 2-9, 2012.

[9] P. W. Macdermid, P. W. Fink, and S. R. Stannard, "Transference of 3D accelerations during cross country mountain biking," Journal of Biomechanics, vol. 47, no. 8, pp. 1829-1837, 2014.

[10] P. W. Macdermid, P. W. Fink, and S. R. Stannard, "The effects of vibrations experienced during road vs. off-road cycling," International Journal of Sports Medicine, 2015.

[11] J. Mester, P. Spitzenfeil, J. Schwarzer, and F. Seifriz, "Biological reaction to vibration-implications for sport," Journal of Science and Medicine in Sport, vol. 2, no. 3, pp. 211-226, 1999.

[12] T. Ishii, Y. Umerura, and K. Kitagawa, "Influences of mountain bike suspension systems on energy supply and performance," Japanese Journal of Biomechanics in Sports and Exercise, vol. 7, pp. 2-9, 2003.

[13] L. M. Sherwin, P. M. O. Owende, C. L. Kanali, J. Lyons, and S. M. Ward, "Influence of tyre inflation pressure on whole-body vibrations transmitted to the operator in a cut-to-length timber harvester," Applied Ergonomics, vol. 35, no. 3, pp. 253-261, 2004.

[14] J. Gordon, J. J. Kauzlarich, and J. G. Thacker, "Tests of two new polyurethane foam wheelchair tires," Journal of Rehabilitation Research and Development, vol. 26, no. 1, pp. 33-46, 1989.

[15] B. J. Sawatzky, W. O. Kim, and I. Denison, "The ergonomics of different tyres and tyre pressure during wheelchair propulsion," Ergonomics, vol. 47, no. 14, pp. 1475-1483, 2004.

[16] P. W. Macdermid, P. W. Fink, and S. R. Stannard, “The influence of tyre characteristics on measures of rolling performance during cross-country mountain biking," Journal of Sports Sciences, vol. 33, no. 3, pp. 277-285, 2015.

[17] R. Van der Plas, Bicycle Technology, Motorbooks International, 1991.

[18] M. Munera, X. Chiementin, S. Crequy, and W. Bertucci, "Physical risk associated with vibration at cycling," Mechanics \& Industry, vol. 15, no. 6, pp. 535-540, 2014.

[19] J. Titlestad, T. Fairlie-Clarke, A. Whittaker, M. Davie, I. Watt, and S. Grant, "Effect of suspension systems on the physiological and psychological responses to sub-maximal biking on simulated smoothand bumpy tracks," Journal of Sports Sciences, vol. 24, no. 2, pp. 125-135, 2006.

[20] V. B. Issurin, "Vibrations and their applications in sport: a review," Journal of Sports Medicine and Physical Fitness, vol. 45, no. 3, pp. 324-336, 2005.
[21] M. Levy and G. A. Smith, "Effectiveness of vibration damping with bicycle suspension systems," Sports Engineering, vol. 8, no. 2, pp. 99-106, 2005. 

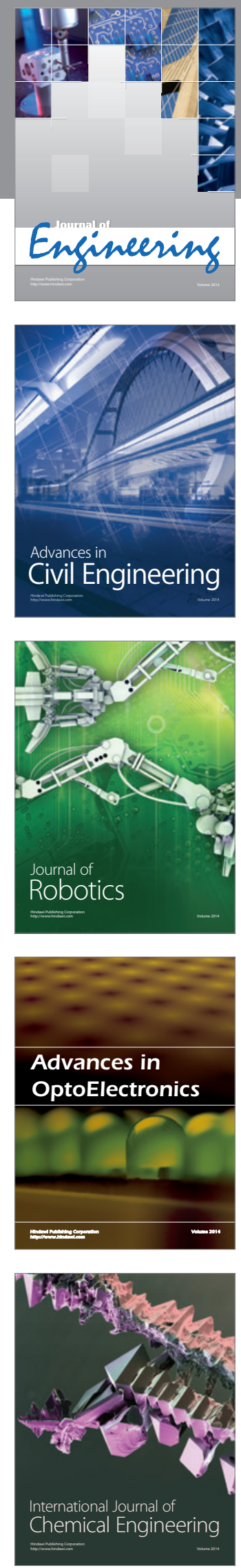

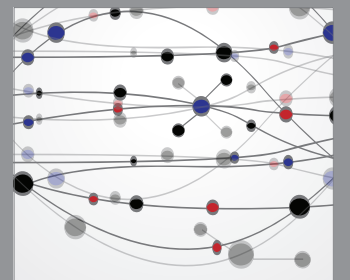

The Scientific World Journal
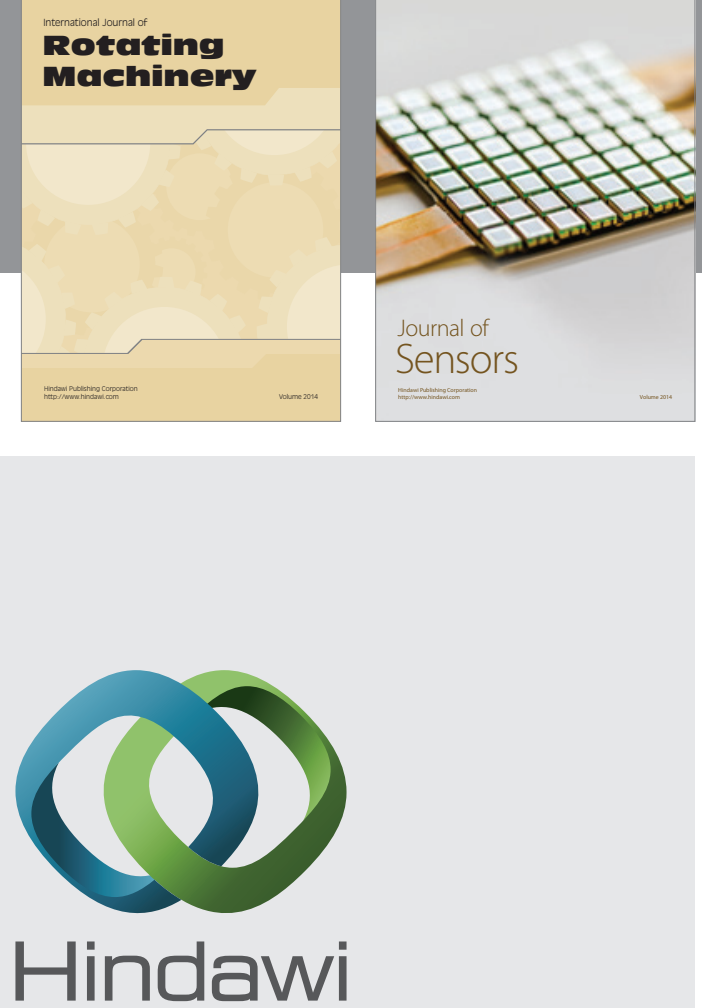

Submit your manuscripts at http://www.hindawi.com
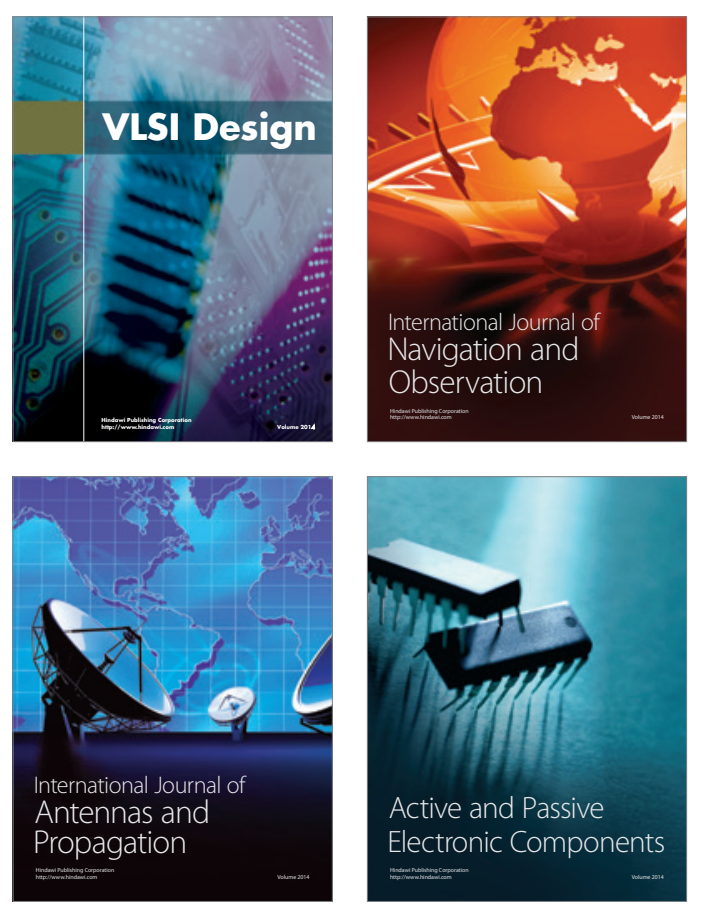
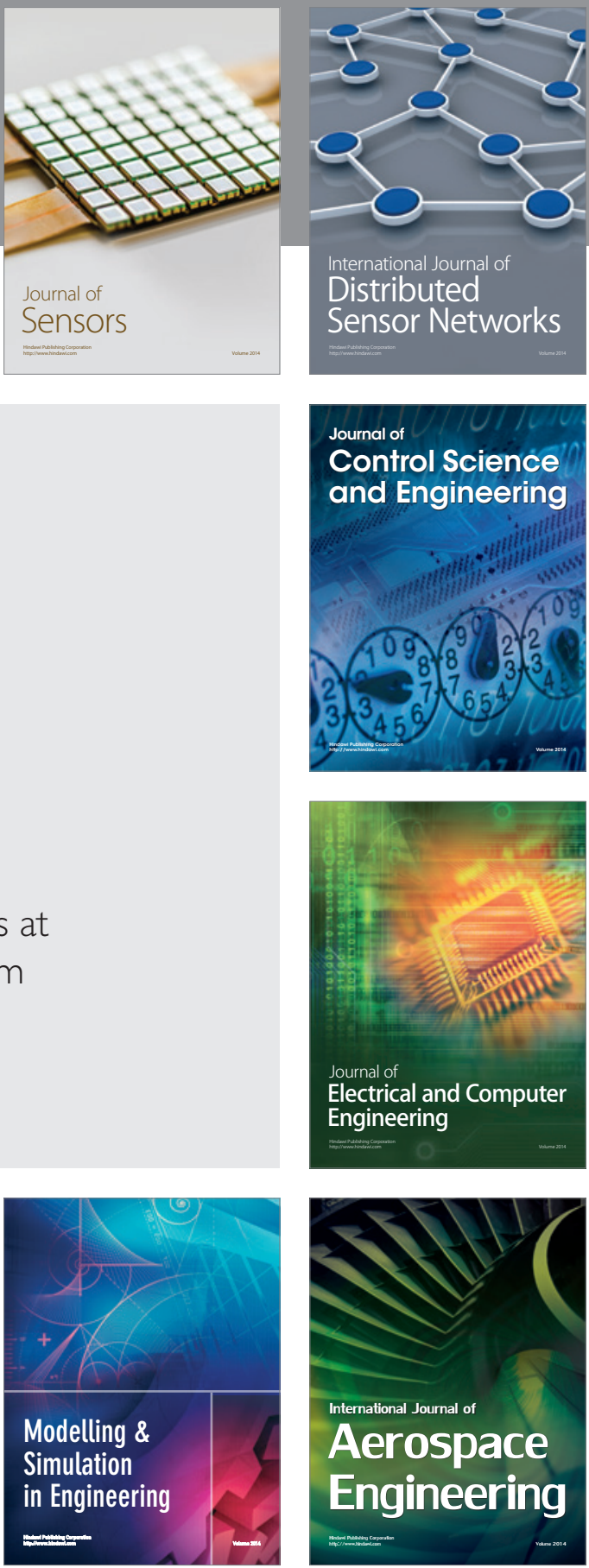

Journal of

Control Science

and Engineering
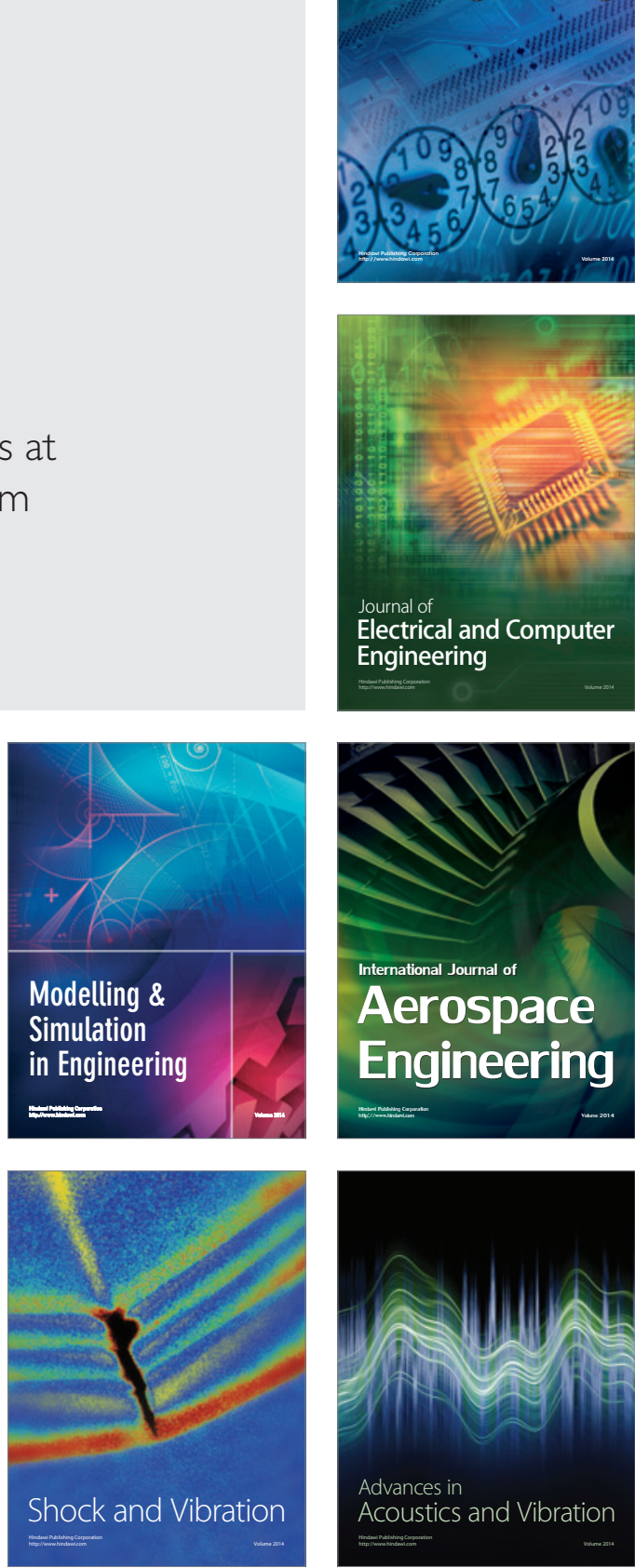